Article

\title{
Characterizing Sources of Small DC Motor Noise and Vibration
}

\author{
Yong Thung Cho \\ Division of Mechanical and Automotive Engineering, Kongju National University, ChunAn, ChoongNam 31080, \\ Korea; cho.yong@gmail.com; Tel.: +82-41-521-9277
}

Received: 22 December 2017; Accepted: 13 February 2018; Published: 15 February 2018

\begin{abstract}
Small direct current (DC) motors are widely used due to their low cost and compact structure. Small DC motors of various designs are available on the market in different sizes. The smaller the motor, the more closely it may be used by individuals. Contrary to the size and simplicity of these motors in terms of structural design, sources of motor noise and vibration can be quite diverse and complicated. In this study, the source of motor noise and vibration was visualized over a very wide range of frequencies. The particle velocity of the motor was reconstructed from nearfield sound pressure measurements of motor noise. In addition to noncontact measurements conducted on a motor running at constant speed, the particle velocity of a stationary motor due to the impulse of an impact hammer was measured with an accelerometer. Furthermore, motor noise was measured under motor run-up conditions with different rotational speeds. As a result, by combination of these three methods, the sources of motor noise were accurately identified over a wide range of frequencies.
\end{abstract}

Keywords: motor noise; micro motor; sound visualization; noise source identification

\section{Introduction}

Small direct current (DC) motors are widely used in toys, automobiles, and personal appliances due to their low cost and compact structure; they typically consist of housing, permanent magnets (stator), armature (rotor), brushes, etc. Various designs for small DC motors are available on the market, with different sizes and numbers of poles. The smaller the motor, the more closely it may be used by individuals. Contrary to the size and simplicity of these motors in terms of structural design, sources of motor noise and vibration are often complicated, tracing back to electro-magnetic forces between armature and permanent magnets or the switching of brushes, housing resonances, bearings, etc., which are quite diverse. Electro-magnetic force and cogging torque are major characteristics of such motors, and these aspects have been actively analyzed [1-3]. Measurement and analytical work related to motor noise sources is relatively few, possibly due to the diversity of motor types and complexity of noise sources. Noise radiated from brushless DC motors has been measured, and resonance from structural and acoustical excitation has been shown in addition to simulation matching [4].

The typical dimensions of a micro motor shown in present work are roughly $30 \mathrm{~mm}$ in both diameter and length. The frequency of sound radiation from these structures ranges from $80 \mathrm{~Hz}$ to higher than $8 \mathrm{kHz}$. Due to their small size, only two or three times larger than a typical transducer, accurately identifying the source of small motor noise is challenging. Acoustical holography has been implemented to visualize the source of motor noise and vibration overall over a very wide range of frequencies by using a relatively small number of microphones. Since the particle velocity of the source surface represents the behavior of a source more accurately than sound pressure on the measurement surface, the particle velocity of a motor was reconstructed from nearfield sound pressure measurements of motor noise. In addition to noncontact measurements conducted on a motor running 
at constant speed, the particle velocity of a stationary motor due to the impulse of an impact hammer on the motor housing was measured with an accelerometer. Furthermore, motor noise was measured under motor run-up conditions with different rotational speeds by varying the motor input voltage, which was useful for characterizing the noise directly related to rotational forces and structural or acoustical resonances.

\section{Measurement and Sound Visualization}

An acoustical holography procedure [5], which also could be described as an inverse system procedure, was implemented to visualize motor noise. Acoustical holography was first introduced for projection of the measurement in spherical coordinates [6]. A version using cylindrical coordinates was later introduced to make measurement surfaces conform more closely to source geometry [7]. An alternative holography procedure, statistically optimized near-field acoustical holography (SONAH), was derived to reduce spatial truncation and the size of the measurement surface [8,9]. SONAH was also modified for projection of measurement in cylindrical coordinates [10]. Cylindrical SONAH was implemented to visualize noise radiated from power seat slide motors [11]. By using fixed reference signals during measurement, a scan can be completed with a relatively small number of microphones for successful acoustical holography reconstruction [12,13]. In the present work, three different types of measurements, cylindrical SONAH, structural impulse using an impact hammer, and a motor run-up test were matched to identify noise sources in a small DC motor.

The sound pressure on a cylindrical surface of radius $r$ can be expressed as

$$
p(r, \phi, z)=\sum_{m=-\infty}^{m=\infty} \frac{1}{2 \pi} \int_{-\infty}^{\infty} P_{m}\left(r, k_{z}\right) e^{i m \phi} e^{i k_{z} z} d k_{z}
$$

where $P_{m}\left(r, k_{\mathrm{z}}\right)$ is the cylindrical wave number spectrum of $p_{m}(r, \phi, z)$ for the $m$ th circumferential component of the sound field, and $k_{z}$ is the axial component of the wave number. The wave number spectrum at radius $r$ can also be expressed in terms of the wave number spectrum of the sound field on a cylindrical source surface of radius $r_{s}$ :

$$
P_{m}\left(r, k_{z}\right)=\frac{H_{m}^{(1)}\left(k_{r} r\right)}{H_{m}^{(1)}\left(k_{r} r_{s}\right)} P_{m}\left(r_{s}, k_{z}\right)
$$

where $H_{m}^{(1)}$ is the $m$ th order Hankel function and the radial wave number is

$$
k_{r}=\left[\begin{array}{ccc}
\sqrt{k^{2}-k_{z}^{2}} & \text { for } & |k| \geq\left|k_{z}\right| \\
i \sqrt{k_{z}^{2}-k^{2}} & \text { for } & |k|<\left|k_{z}\right|
\end{array}\right.
$$

with $k=\omega / c, \omega$ being the angular frequency and $c$ the ambient sound speed. The spatial distribution of the sound pressure at radius $r$ can then be found by inverse transformation of the projected wave number spectrum at $r$ :

$$
p(r, \phi, z)=\sum_{m=-\infty}^{m=\infty} \frac{1}{2 \pi} \int_{-\infty}^{\infty} \frac{H_{m}^{(1)}\left(k_{r} r\right)}{H_{m}^{(1)}\left(k_{r} r_{s}\right)} P_{m}\left(r_{s}, k_{z}\right) e^{i m \phi} e^{i k_{z} z} d k_{z}
$$

Now, define a three-dimensional cylindrical wave function, $\Phi_{k_{z}, m}(r, \phi, z)$, as

$$
\Phi_{k_{z}, m}(\mathbf{r})=\Phi_{k_{z}, m}(r, \phi, z) \equiv \frac{H_{m}^{(1)}\left(k_{r} r\right)}{H_{m}^{(1)}\left(k_{r} r_{s}\right)} e^{i m \phi} e^{i k_{z} z}, \quad r \geq r_{s}
$$

The sound pressure on the cylindrical surface at radius $r$ can then be expressed using the wave function, $\Phi_{k_{z}, m}(r, \phi, z)$, as 


$$
p(\mathbf{r})=\frac{1}{2 \pi} \sum_{m=-\infty}^{m=\infty} \int_{-\infty}^{\infty} P_{m}\left(r_{s}, k_{z}\right) \Phi_{k_{z}, m}(\mathbf{r}) d k_{z}
$$

When $\mathbf{r}_{h}$ is used to represent positions on the measurement (or hologram) surface at $r=r_{h}>r_{s}$, an expression is obtained for the pressure on the hologram surface:

$$
p\left(\mathbf{r}_{h}\right)=\frac{1}{2 \pi} \sum_{m=-\infty}^{m=\infty} \int_{-\infty}^{\infty} P_{m}\left(r_{s}, k_{z}\right) \Phi_{k_{z}, m}\left(\mathbf{r}_{h}\right) d k_{z} .
$$

Assume that sound pressure $p(\mathbf{r})$ at an arbitrary position is represented as a linear combination of the measured sound pressure data, $p\left(\mathbf{r}_{h, j}\right)$ :

$$
p(\mathbf{r}) \approx \sum_{j=1}^{J} c_{j}(\mathbf{r}) \cdot p\left(\mathbf{r}_{h, j}\right) .
$$

The same coefficients $c_{j}$ in Equation (8) also provide a good estimation for the cylindrical wave functions:

$$
\Phi_{k_{z q}, m}(\mathbf{r}) \approx \sum_{j=1}^{J} c_{j}(\mathbf{r}) \Phi_{k_{z q}, m}\left(\mathbf{r}_{h, j}\right), \quad m=1 \ldots . \quad M, \quad q=1 \ldots . N .
$$

The various quantities involved in the calculation are defined in the form of matrices and vectors as

$$
\mathbf{A} \equiv\left[\Phi_{k_{z q}, m}\left(\mathbf{r}_{h, j}\right)\right], \quad \boldsymbol{\alpha}(\mathbf{r}) \equiv\left[\Phi_{k_{z q}, m}(\mathbf{r})\right], \quad \mathbf{c}(\mathbf{r}) \equiv\left[c_{j}(\mathbf{r})\right] .
$$

Equation (9) can then be expressed in matrix form as

$$
\alpha(\mathbf{r}) \approx \mathbf{A c}(\mathbf{r})
$$

The regularized least squares solution for the weight vector, $\mathbf{c}(\mathbf{r})$, is then

$$
\mathbf{c}(\mathbf{r})=\left(\mathbf{A}^{+} \mathbf{A}+\theta^{2} \mathbf{I}\right)^{-1} \mathbf{A}^{+} \boldsymbol{\alpha}(\mathbf{r}),
$$

where $^{+}$denotes the Hermitian or conjugate transpose, $\mathbf{I}$ is the identity matrix, and the regularization parameter, $\theta$, is

$$
\theta^{2}=\left[\mathbf{A}^{+} \mathbf{A}\right]_{i i} 10^{-S N R / 10},
$$

where SNR, the regularization parameter, depends on the signal-to-noise ratio of the measurement signal and the reconstruction location from the measurement. The subscript $i i$ is used here to denote the diagonal elements of a matrix. The reconstructed pressure, $p(\mathbf{r})$, is expressed as

$$
p(\mathbf{r}) \approx \sum_{j=1}^{J} c_{j}(\mathbf{r}) p\left(\mathbf{r}_{h, j}\right)=\mathrm{p}^{\mathrm{T}}\left(\mathbf{r}_{h}\right) \mathbf{c}(\mathbf{r})=\mathrm{p}^{\mathrm{T}}\left(\mathbf{r}_{h}\right)\left(\mathbf{A}^{+} \mathbf{A}+\theta^{2} \mathbf{I}\right)^{-1} \mathbf{A}^{+} \boldsymbol{\alpha}(\mathbf{r}),
$$

where $\mathbf{p}\left(\mathbf{r}_{h}\right)$ is the vector of measured pressures.

The radial particle velocity on the reconstruction surface, $u_{r}(\mathbf{r})$, can be found using Euler's equation:

$$
u_{r}(\mathbf{r})=\frac{1}{i \rho_{o} \omega} \frac{\partial p(\mathbf{r})}{\partial r} .
$$

By substituting the estimated spatial distribution of the sound pressure from Equation (14) into Equation (15), the radial particle velocity, $u_{r}(\mathbf{r})$, is obtained as 


$$
\begin{aligned}
u_{r}(\mathbf{r}) & \approx \frac{1}{i \rho_{0} \omega} \frac{\partial}{\partial r}\left[\mathrm{p}^{\mathrm{T}}\left(\mathbf{r}_{h}\right)\left(\mathbf{A}^{+} \mathbf{A}+\theta^{2} \mathbf{I}\right)^{-1} \mathbf{A}^{+} \boldsymbol{\alpha}(\mathbf{r})\right] \\
& =\mathrm{p}^{\mathrm{T}}\left(\mathbf{r}_{h}\right)\left(\mathbf{A}^{+} \mathbf{A}+\theta^{2} \mathbf{I}\right)^{-1} \mathbf{A}^{+} \boldsymbol{\beta}(\mathbf{r})=\mathrm{p}^{\mathrm{T}}\left(\mathbf{r}_{h}\right) \mathbf{d}(\mathbf{r}),
\end{aligned}
$$

where $\mathbf{d}(\mathbf{r})$ is the transfer matrix between measurement pressure and the reconstructed particle velocity, and the vector $\beta(\mathbf{r})$ is defined as

$$
\boldsymbol{\beta}(\mathbf{r}) \equiv \frac{1}{i \rho_{o} \omega} \frac{\partial \boldsymbol{\alpha}(\mathbf{r})}{\partial r}=\left[\frac{1}{i \rho_{o} \omega} \frac{\partial}{\partial r} \Phi_{k_{z q}, m}(\mathbf{r})\right] .
$$

The elements of $\beta(\mathbf{r})$ are modified cylindrical wave functions, which by use of Equation (5) can be expressed as

$$
\Phi_{k_{z q}, m}^{u}(r, \phi, z) \equiv \frac{-i k_{r}}{\rho_{o} \omega} \frac{H_{m}^{(1)^{\prime}}\left(k_{r} r\right)}{H_{m}^{(1)}\left(k_{r} r_{s}\right)} e^{i m \phi} e^{i k_{z q} z},
$$

where the superscript prime denotes differentiation with respect to the function's argument and $\rho_{\mathrm{o}}$ is the ambient density. The vector $\beta(\mathbf{r})$ can then be written as

$$
\boldsymbol{\beta}(\mathbf{r}) \equiv\left[\Phi_{k_{z q}, m}^{u}(\mathbf{r})\right] .
$$

Now, pressure and particle velocity can be reconstructed at other surfaces, such as source surfaces, from the measurement pressure. So, more detailed and accurate information about the source can be obtained using the reconstructed properties than with measurement pressure alone.

Particle velocity of the motor housing due to impulsive force of impact hammer can be measured directly using the accelerometer for undamped systems or system with small damping. Unit impulse or the delta function, $\delta(t)$, is defined as $[14,15]$

$$
\delta(t-\xi)=0,
$$

for all $t$, except $t=\xi$ and delta function becomes very large or infinite when $t=\xi$, and its integral becomes unity, which is

$$
\int_{0}^{\infty} \delta(t-\xi) d t=1,
$$

for positive $\xi$. So, the time integral of delta function multiplied by function $f(t)$ can be evaluated as

$$
\int_{0}^{\infty} f(t) \delta(t-\xi) d t=f(\xi) .
$$

From the equation of motion of a point mass with external force, $F$, applied,

$$
F d t=m d v,
$$

impulse is represented as,

$$
\hat{F}=F \Delta t=m \Delta v=m v .
$$

When the mass is initially at rest, $v$ is the velocity of mass after impulse. Undamped free vibration solution of a spring-mass system initially located at origin is [15]

$$
x=\frac{\dot{x}(0)}{\omega_{n}} \sin \omega_{n} t,
$$

where $x$ is the displacement. Since velocity of mass after impulse, $v$, is the initial velocity, the displacement $x$ can be represented by using the impulse and mass, which is 


$$
x=\frac{v}{\omega_{n}} \sin \omega_{n} t=\frac{\hat{F}}{m \omega_{n}} \sin \omega_{n} t=-\frac{\hat{F}}{m \omega_{n}} \operatorname{Im}\left(e^{-j \omega_{n} t}\right) .
$$

By differentiation of the displacement in time, and relationship between the velocity and the acceleration is reduced to

$$
\dot{x}=-\frac{1}{j \omega_{n}} \ddot{x} .
$$

As a result, the particle velocity of undamped or small damping systems can be estimated from the measurement of the acceleration of impulse excitation.

\section{Measurement Description}

Sound pressure of a motor rotating at constant speed was measured on a cylindrical surface to reconstruct the particle velocity of a source surface. In addition, the particle velocity of stationary motor housing due to an impulse by an impact hammer on the housing was measured with an accelerometer. Also, motor noise was measured under motor run-up conditions with different rotational speeds by varying the motor input voltage.

The exterior and interior of a small DC motor with brushes used for noise measurements are shown in Figure 1. The exterior diameters of $12 \mathrm{~V}$ DC motor housing and armature were $34 \mathrm{~mm}$ and $24 \mathrm{~mm}$, respectively. The lengths of the motor housing and armature were $30 \mathrm{~mm}$ and $10 \mathrm{~mm}$, respectively. Two brushes were located at the bottom cap as shown in Figure 1b. In the present work, the location of the brushes is referred to as the bottom, and the location of the shaft is referred to as the top. The two permanent magnets were restrained inside the motor housing, and the rotor consisted of armature with three poles. Three ventilation holes on the top surface of the motor housing are shown in Figure 1b,c.

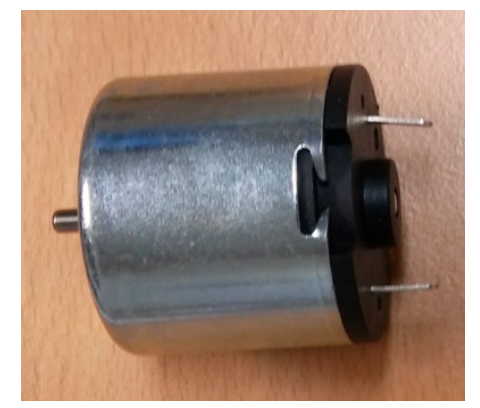

(a)

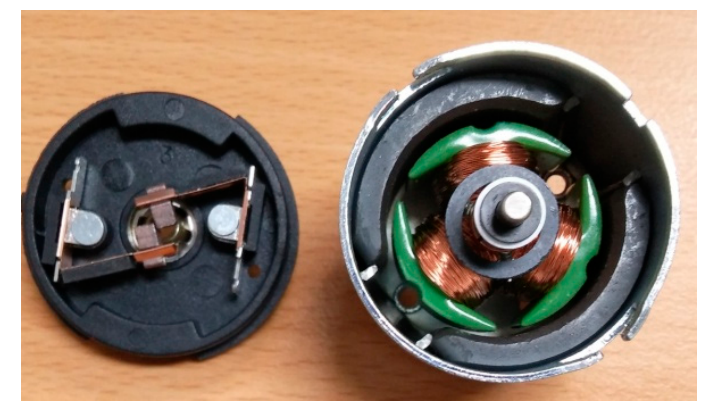

(b)

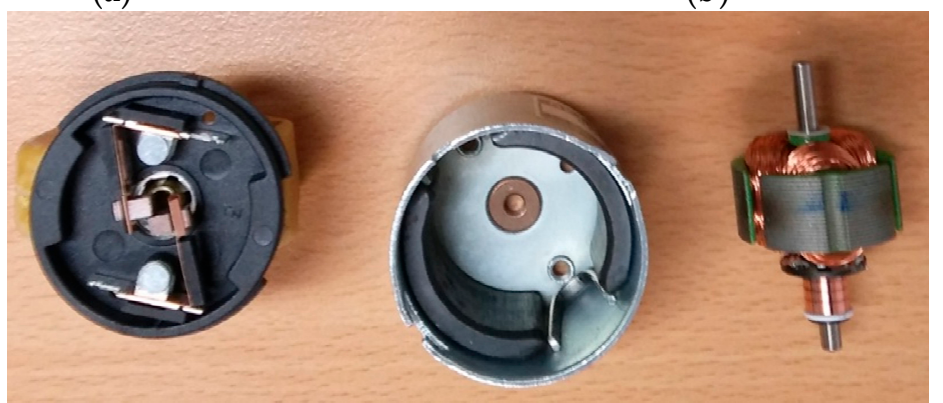

(c)

Figure 1. The exterior and interior of a small direct current (DC) motor with brushes used for noise measurement: (a) small DC motor exterior; (b) three-pole rotor installed inside the motor housing with two permanent magnets and the brush cap open; (c) three-pole rotor with grooved armature separated from the motor housing. 
Also, the armature was grooved to prevent the ventilation holes from being closed while the motor was rotating. The exterior and interior of a small DC motor with angular coordinates used for noise measurement are shown in Figure 2. The locations of three ventilation holes are clearly shown in Figure 2, at $0^{\circ}, 90^{\circ}$, and $180^{\circ}$. The small DC motor and microphones positioned for measurement are shown in Figure 3. A stationary reference microphone was also positioned above the center of the motor shaft, and scanning microphones were located in parallel to the axial direction of the motor, as shown in Figure 3. The scanning microphone position shown in Figure 3 represents the $0^{\circ}$ mark, which is consistent with the coordinates shown in Figure 2. The scanning microphones were rotated counter-clockwise to obtain measurements in increments of $15^{\circ}$. The total number of measurements in the circumferential direction was twenty-four. One stationary reference microphone was located on the top of the motor shaft, and four scanning microphones were located with $2 \mathrm{~cm}$ spacing in the axial direction. Relatively few microphones were used for measurement since the motor was relatively small. However, the entire cylindrical source surface around the motor was measured.

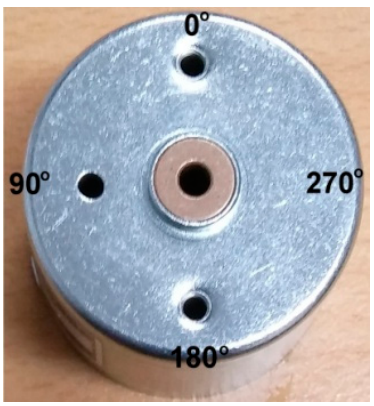

(a)

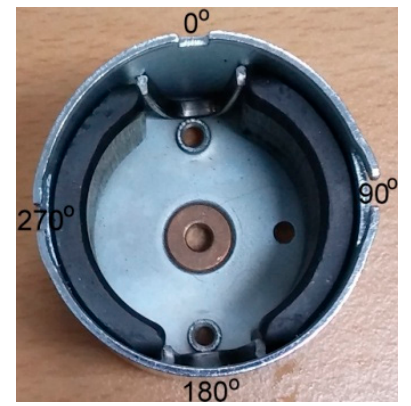

(b)

Figure 2. The exterior and interior of small DC motor housing with angular coordinates used for noise measurement: (a) exterior of the motor housing, top view; (b) interior of the motor housing, bottom view.

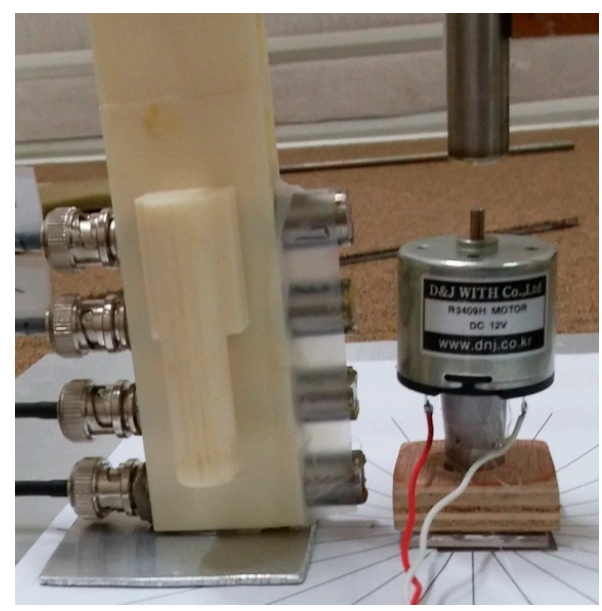

Figure 3. A small DC motor and measurement microphones positioned in the vicinity of the motor. A stationary reference microphone positioned above the center of the motor shaft, and scanning microphones located in parallel to the axial direction of the motor.

Accelerometer model PCB 353B15 (PCB Piezotronics, Inc., Depew, NY, USA) and impact hammer model PCB 086C03 (PCB Piezotronics, Inc., Depew, NY, USA) were used for motor housing acceleration measurement. The location of impact was at the $0^{\circ}$ mark on the motor housing center, and measurements were taken at $90^{\circ}$ and $180^{\circ}$ on the motor housing center relative to the location of impact. Output from the accelerometer and impact hammer was gathered via the input of a 
signal conditioner model PCB 482C (PCB Piezotronics, Inc., Depew, NY, USA). Output from the signal conditioner was directed as analog input to a data acquisition model NI-USB-6363 (National Instruments Corporation, Austin, TX, USA). Finally, output from the NI-USB-6363 was sent to a laptop computer, model Acer Aspire 5736Z-4801 (Acer Inc., New Taipei City, Taiwan), and the measurement data was saved on the laptop.

A total of five microphones, including four scanning and one fixed microphones as shown in Figure 3, were used for motor sound pressure measurements. The entire cylindrical surface was scanned while the motor was running at constant speed at $12 \mathrm{~V}$. For motor run-up operation from $6 \mathrm{~V}$ to $15 \mathrm{~V}$, the position shown in Figure 3 represents the $0^{\circ}$ mark. For run-up operation of the motor, sound pressure was measured only at $0^{\circ}$. The microphones were calibrated at $1000 \mathrm{~Hz}, 94 \mathrm{~dB}$, and connected to a microphone amplifier. Output from the microphone amplifier was directed to the NI-USB-6363, which was connected to a laptop computer, and the measurement data was saved on the laptop.

All signals in the present work were sampled at $44.1 \mathrm{kHz}$. The Hann window was applied to measurements from the microphones. A uniform window was applied to signals from the accelerometer and impact hammer. Microphone spacing in the axial direction was $2 \mathrm{~cm}$. The radius of measurement was $2.7 \mathrm{~cm}$, which was $1 \mathrm{~cm}$ from the motor housing surface. The angular increment of measurement was $15^{\circ}$, and the corresponding measurement spacing in the angular direction was about $0.707 \mathrm{~cm}$. Due to the relatively small radius of the motor and measurement surface, measurement spacing in the angular direction was smaller than in the axial direction.

It would be ideal to take all measurements in free boundary condition. However, for convenience, all measurements of sound pressure and acceleration of the motor shown in the present work were taken with the motor located on a relatively rigid boundary, a $20 \mathrm{~mm}$ thick aluminum plate.

\section{Motor Excitation Forces}

Electro-magnetic force defines one major characteristic of a motor and is closely related to motor noise and vibration; it has been actively analyzed [1-5]. Any periodic function can be represented as the sum of harmonic functions of multiples of fundamental frequency [16]. Moreover, a periodic function with fundamental frequency, $f_{\mathrm{f}}$, can be decomposed to a harmonic function of multiples of fundamental frequencies, as

$$
f_{\mathrm{p}}=m f_{\mathrm{f}},
$$

where $f_{\mathrm{p}}$ is the frequency of the periodic function and $m$ is a positive integer.

Unbalanced mass or forces of armature, possibly due to geometric non-symmetry during the manufacturing process, are also a potential cause of motor noise and vibration. The frequency of excitation due to an unbalanced force of armature, $f_{\mathrm{u}}$, is

$$
f_{\mathrm{u}}=m f_{\mathrm{r}},
$$

where $f_{\mathrm{r}}$ is motor rotational speed in revolutions per second. For $m=1, f_{\mathrm{u}}$ is the fundamental frequency of motor rotation. The frequency of excitation due to electro-magnetic force by armature at a point on the housing, $f_{\mathrm{e}}$, is

$$
f_{\mathrm{e}}=m p f_{\mathrm{r}}
$$

where $p$ is the number of poles of armature, which is three for the motor shown in the present work. However, the frequency of the entire housing, $f_{\mathrm{h}}$, is

$$
f_{\mathrm{h}}=m L_{\mathrm{cmh}} f_{\mathrm{r}}
$$

where $L_{\mathrm{cmh}}$ is the least common multiple of the number of poles in armature and housing, which is six for the motor shown in present work. 
The frequency of excitation due to a ventilation fan, $f_{\mathrm{v}}$, is

$$
f_{\mathrm{v}}=m q f_{\mathrm{r}}
$$

where $q$ is the number of blades in the ventilation fan. However, there was no ventilation or cooling fan in the motor used here. The frequency of excitation from forces from the brushes due to switching in the commutator, $f_{\mathrm{b}}$, is

$$
f_{\mathrm{b}}=m L_{\mathrm{cmb}} f_{\mathrm{r}},
$$

where $L_{\mathrm{cmb}}$ is the least common multiple of the number of poles and brushes, which is six for the motor shown in the present work. The major forcing frequencies of the excitation are summarized in Table 1.

\begin{tabular}{|c|c|}
\hline \multirow{4}{*}{ Number of Poles } & $p=3$ \\
\hline & $q=3$ \\
\hline & $L_{\mathrm{cmh}}=6$ \\
\hline & $L_{\mathrm{cmb}}=6$ \\
\hline Forcing Frequencies & $\begin{array}{c}f_{\mathrm{u}}=m f_{\mathrm{r}} \\
f_{\mathrm{e}}=m p f_{\mathrm{r}}=3 m f_{\mathrm{r}} \\
f_{\mathrm{h}}=m L_{\mathrm{cmh}} f_{\mathrm{r}}=6 m f_{\mathrm{r}} \\
f_{\mathrm{v}}=m q f_{\mathrm{r}}=3 m f_{\mathrm{r}} \\
f_{\mathrm{b}}=m L_{\mathrm{cmb}} f_{\mathrm{r}}=6 m f_{\mathrm{r}}\end{array}$ \\
\hline
\end{tabular}

Table 1. Major forcing frequencies of the excitation.

\section{Measurement Results}

Motor noise was measured under motor run-up conditions with different rotational speeds by varying the motor input voltage, which was useful for characterizing the noise directly related to rotational forces and structural or acoustical resonances. Also, the response of a stationary motor housing surface due to an impulse from an impact hammer on the motor housing was measured with an accelerometer. The sound pressure of a motor rotating at constant speed was also measured on a cylindrical surface to reconstruct the particle velocity of a source surface.

Motor noise without load was measured at different rotational speeds by varying the motor input voltage as shown in Figure 4. The motor input voltage was increased from $6 \mathrm{~V}$ to $15 \mathrm{~V}$ with $0.3 \mathrm{~V}$ increments, where the nominal motor input voltage was $12 \mathrm{~V}$. The location of the microphones was at the $0^{\circ}$ mark, as shown in Figures 2 and 3. The results of measurements at different locations, such as the bottom end cap, housing center, and shaft center at the top, with different upper frequency ranges of $10 \mathrm{kHz}$ and $2 \mathrm{kHz}$ are shown in Figure 4. No weighting or linear weighting on the decibel scale were applied to the measurement results shown in Figure 4. The measurements from three different locations were relatively similar especially around $5000 \mathrm{~Hz}$ and the third motor rotating speeds. However, the measurement results at the motor housing center were the clearest compared to the results from other locations, as shown in Figure 4. Higher peaks were observed around $5000 \mathrm{~Hz}$ over a wide range of motor rotating speeds, especially at higher rotating speeds, which indicates that a major source of noise may be motor housing resonance around $5000 \mathrm{~Hz}$, which is shown clearly in Figure $4 \mathrm{c}$. In contrast, based only on motor run-up measurements, strong peaks near the first and third order of motor rotating speeds are clearly shown in Figure $4 \mathrm{~d}$, possibly due to unbalanced mass during rotation and electromagnetic forces between the armature and permanent magnets. Resonance around $7000 \mathrm{~Hz}$ was very clearly shown from the measurement on the top of the housing at motor shaft center, as shown in Figure 4e, which implied that the resonance was related to the top part of the motor. Sources of noise were also confirmed and identified by measurement of the particle velocity of 
the motor housing surface due to an impulse from an impact hammer and reconstruction of particle velocity of the motor housing surface from sound pressure measurements.

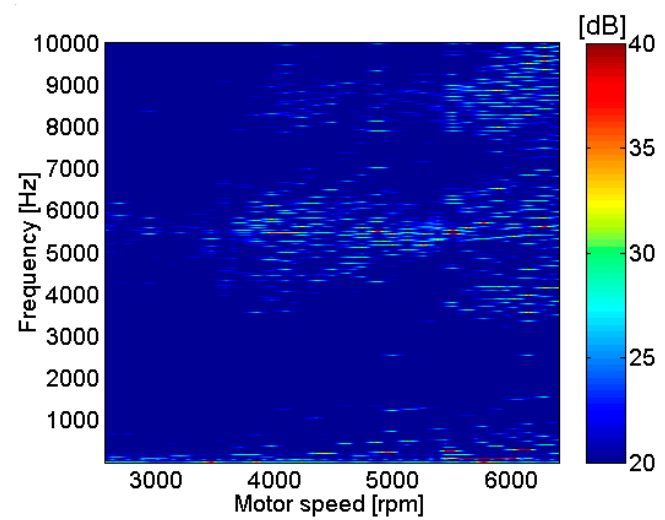

(a)

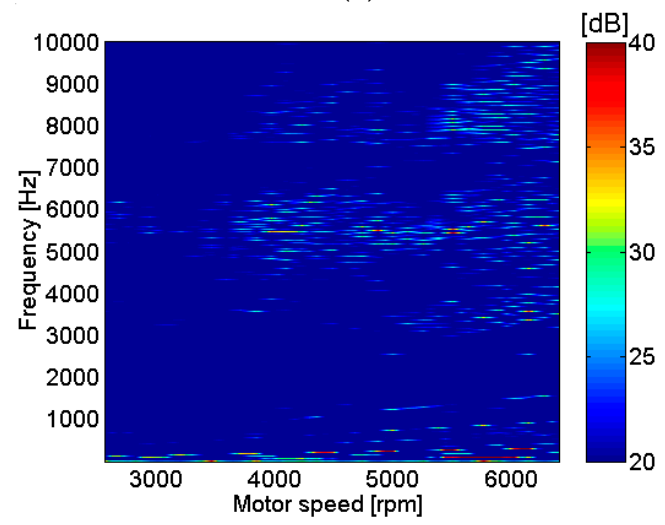

(c)

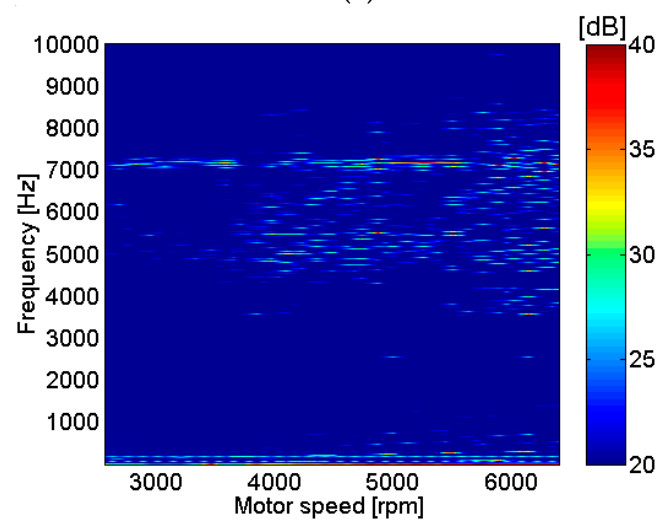

(e)

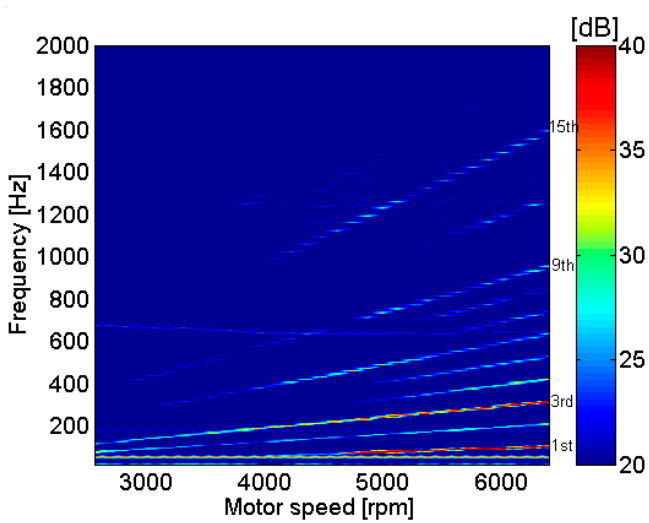

(b)

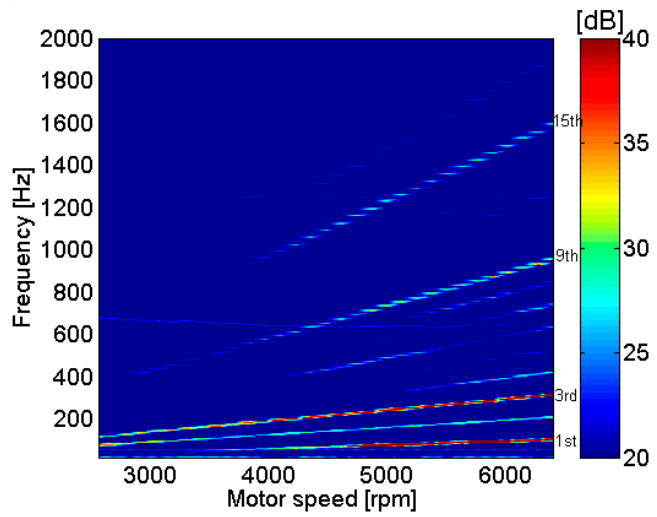

(d)

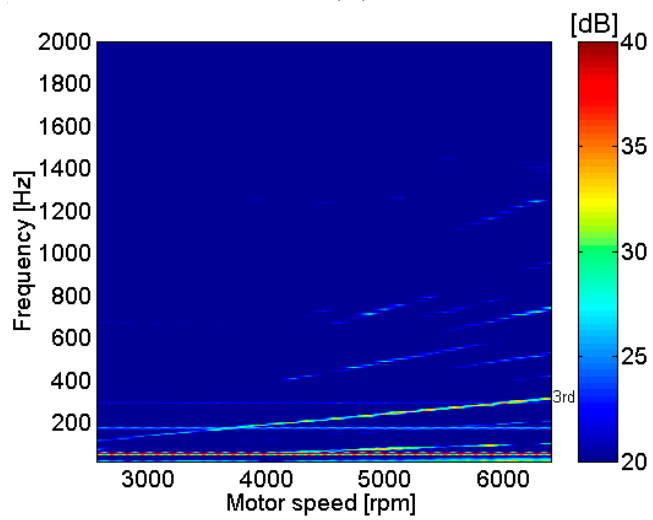

(f)

Figure 4. Motor noise measurement at different locations for motor run-up operation from 6 to $15 \mathrm{~V}$ with aluminum base plate support: (a) bottom end cap; (b) bottom end cap; (c) motor housing center; (d) motor housing center; (e) motor shaft center top; (f) motor shaft center top.

The response of the motor housing surface at different locations due to an impulse from an impact hammer is shown in Figure 5. The motor housing was excited with an impulse from an impact hammer at $0^{\circ}$ on the motor housing center, and measurements were taken at $90^{\circ}$ and $180^{\circ}$ with the same accelerometer, sequentially. The magnitude of the excitation force, the impulse from the impact hammer, is shown in Figure 5a,c. Even though a hammer with a steel tip was used to excite the housing at higher frequencies, the magnitude of the excitation force was relatively small at frequencies above $5000 \mathrm{~Hz}$. However, the particle velocity measurements shown in Figure $5 \mathrm{~b}$,d indicate the possibility of 
structural resonance of housing at frequencies around $5000 \mathrm{~Hz}$ and $7000 \mathrm{~Hz}$. Due to the fairly weak impulse, responses above $5000 \mathrm{~Hz}$ were very noisy both at $90^{\circ}$ and $180^{\circ}$, but peak frequencies matched well with motor run-up measurements. The impact hammer used in present work, PCB 089C03 (PCB Piezotronics, Inc., Depew, NY, USA), was a general purpose impact hammer with frequency range of $8 \mathrm{kHz}$, and was readily available [16]. However, if the smaller impact hammer was used instead, possibly the higher input force and lower noise level in measured particle velocity in a high frequency region, especially above $4 \mathrm{kHz}$, should be shown.

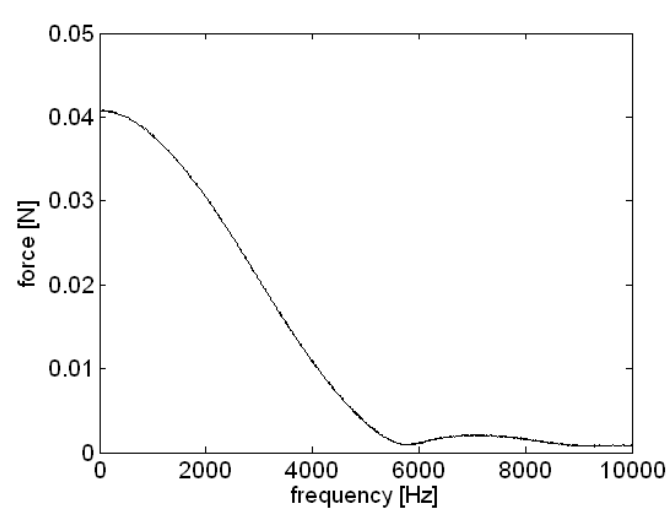

(a)

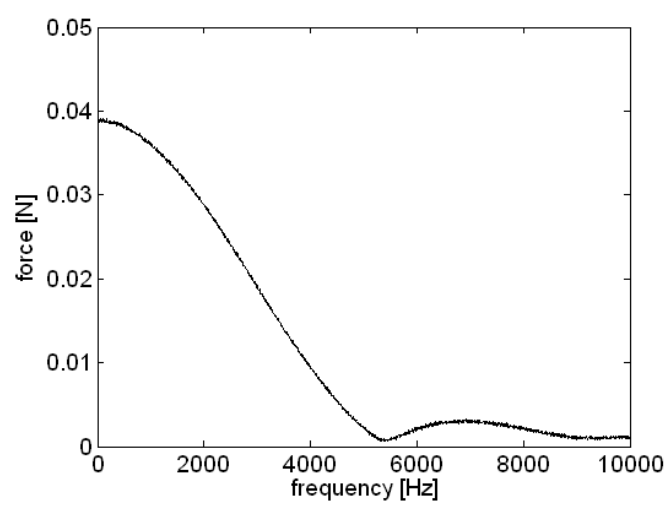

(c)

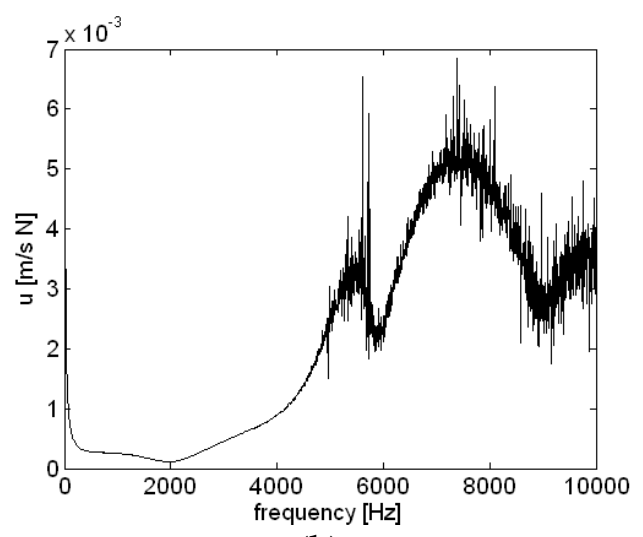

(b)

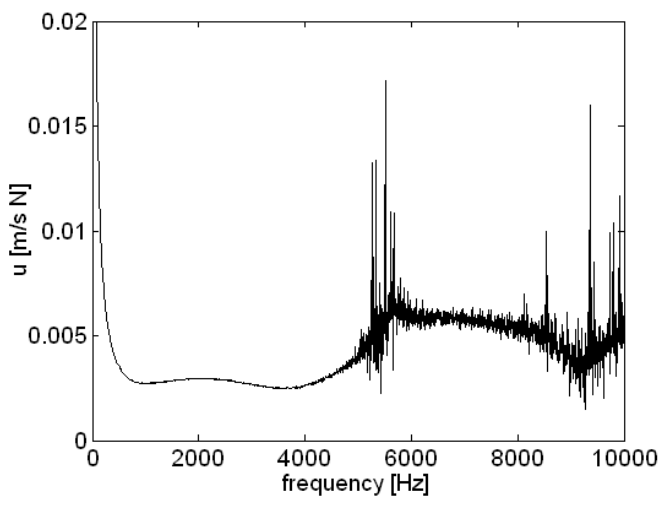

(d)

Figure 5. Response of the motor housing at different locations due to external excitation from a hammer: (a) $90^{\circ}$, force; (b) $90^{\circ}$, particle velocity; (c) $180^{\circ}$, force; (d) $180^{\circ}$, particle velocity.

The sound pressure of a motor rotating at constant speed with motor input voltage of $12 \mathrm{~V}$ was measured on a cylindrical surface to reconstruct the particle velocity of source surfaces. The microphones shown in Figure 3 were used to scan the sound pressure at twenty-four equally spaced locations in the circumferential direction on a cylindrical surface of radius $2.7 \mathrm{~cm}$, which was $1 \mathrm{~cm}$ larger than the motor housing radius. Measurement increments in the axial direction were $2 \mathrm{~cm}$, so as to avoid spatial aliasing in the axial direction the highest frequency was $8575 \mathrm{~Hz}$, with the speed of sound in air being $343 \mathrm{~m} / \mathrm{s}$. Angular measurement increments were $15^{\circ}$, and measurement spacing in the angular direction was about $0.707 \mathrm{~cm}$, so as to avoid spatial aliasing in the circumferential direction the highest frequency was $24257 \mathrm{~Hz}$. As a result, $8575 \mathrm{~Hz}$ was considered the highest frequency to avoid spatial aliasing during reconstruction of particle velocity for measurements in the present work.

Spatially-averaged motor noise measurements for motor operation at $12 \mathrm{~V}$ are shown in Figure 6. The same results over a different frequency range are shown in Figure $6 a, b$. From the highest peaks of the spatially-averaged measurement pressure shown in Figure 6, sixteen frequencies were chosen, and the corresponding reconstructed source particle velocities are presented in Figure 7 . All of the results shown in Figures 6 and 7 are based on an A-weighted decibel level. 


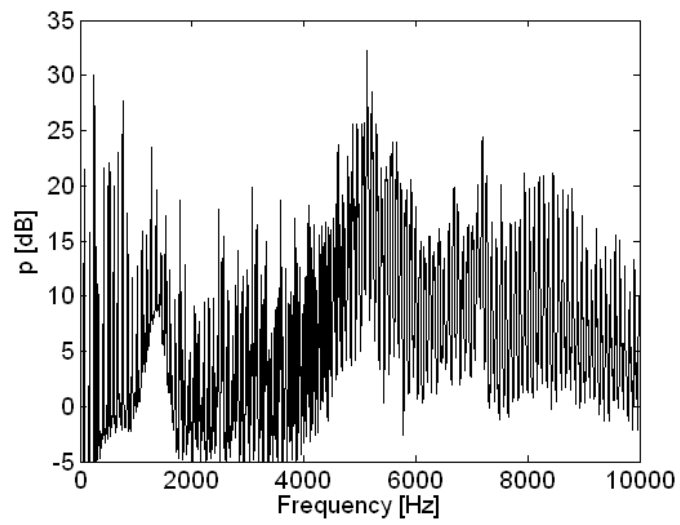

(a)

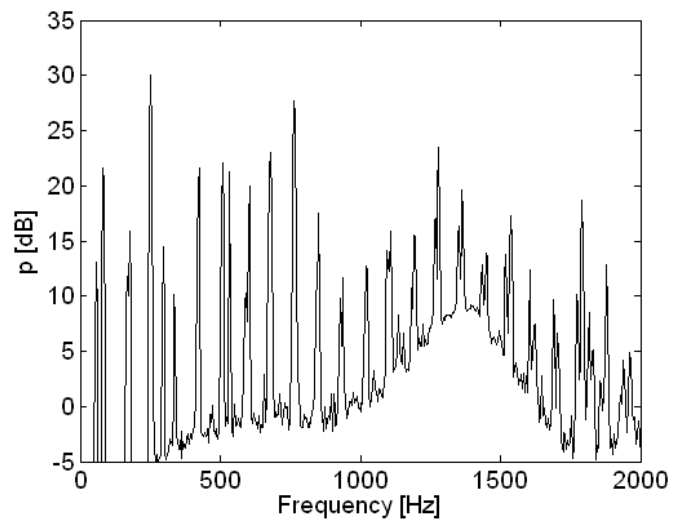

(b)

Figure 6. Spatially-averaged motor noise measurements for motor operation at $12 \mathrm{~V}$ with different frequency ranges: (a) 0-10000 Hz; (b) 0-2000 Hz.

Based on the reconstructed source particle velocity results from the measurements shown in Figure 7, the motor was rotating at a speed of approximately 5120 revolutions per minute without load when $12 \mathrm{~V}$ were supplied. A description of the source particle velocity reconstruction for the motor is summarized and shown in Table 2.

Table 2. Description of source particle velocity reconstruction.

\begin{tabular}{ccc}
\hline Frequency & Order & Description of Source \\
\hline $84 \mathrm{~Hz}$ & $1 \mathrm{st} f_{\mathrm{r}}$ & Unbalanced force \\
$252 \mathrm{~Hz}$ & 3rd $f_{\mathrm{r}}, 1 \mathrm{st} f_{\mathrm{e}}$ & Top ventilation \\
$508 \mathrm{~Hz}$ & 6th $f_{\mathrm{r}}, 1 \mathrm{st} f_{\mathrm{b}}$ & Brush switching \\
$532 \mathrm{~Hz}$ & & Base reflection \\
$764 \mathrm{~Hz}$ & $9 \operatorname{th} f_{\mathrm{r}}, 3 \mathrm{rd} f_{\mathrm{e}}$ & Electro-magnetic force \\
$1024 \mathrm{~Hz}$ & 12th $f_{\mathrm{r}}, 4 \operatorname{th} f_{\mathrm{e}}$ & Electro-magnetic force \\
$1280 \mathrm{~Hz}$ & $15 \operatorname{th} f_{\mathrm{r}}, 5 \operatorname{th} f_{\mathrm{e}}$ & Electro-magnetic force \\
$1360 \mathrm{~Hz}$ & $16 \operatorname{th} f_{\mathrm{r}}$ & Internal resonance \\
$1452 \mathrm{~Hz}$ & & Base reflection \\
$1792 \mathrm{~Hz}$ & $21 \mathrm{st} f_{\mathrm{r}}, 7 \mathrm{th} f_{\mathrm{e}}$ & Electro-magnetic force \\
$3076 \mathrm{~Hz}$ & 36th $f_{\mathrm{r}}, 12 \operatorname{th} f_{\mathrm{e}}$ & Base reflection \\
$4680 \mathrm{~Hz}$ & & Bottom cap \\
$4956 \mathrm{~Hz}$ & $58 \operatorname{th} f_{\mathrm{r}}$ & Internal resonance \\
$5124 \mathrm{~Hz}$ & 60th $f_{\mathrm{r}}, 20 \operatorname{th} f_{\mathrm{e}}$ & Housing bottom $n=2$ mode \\
$7192 \mathrm{~Hz}$ & 84th $f_{\mathrm{r}}, 28 \operatorname{th} f_{\mathrm{e}}$ & Housing center $n=2$ mode \\
$8456 \mathrm{~Hz}$ & $99 \operatorname{th} f_{\mathrm{r}}, 33 \mathrm{rd} f_{\mathrm{e}}$ & Base reflection \\
\hline
\end{tabular}

Sound radiation from the motor housing due to an unbalanced force or mass at $84 \mathrm{~Hz}$, which corresponds to a first-order rotation speed, is clearly shown in Figure 7a. Sound radiation from cooling holes on the top surface of the motor is clearly shown at $252 \mathrm{~Hz}$ in Figure $7 \mathrm{~b}$. The location of three holes is shown in Figures 2 and 3. Even though there was no cooling fan inside the motor, $252 \mathrm{~Hz}$ corresponded to the first order of ventilation frequency considering the number of poles in the armature. Also, $252 \mathrm{~Hz}$ corresponded to the first-order electro-magnetic force excitation frequency. However, it is clearly shown in Figure $7 \mathrm{~b}$ that the sound radiation from the three holes on the upper surface of the housing was more dominant than other sources of noise. Radiated sound due to the switching of brushes at $508 \mathrm{~Hz}$ is clearly shown in Figure 7c. The brushes were located on the bottom surface of the motor at $120^{\circ}$ and $300^{\circ}$. A frequency of $508 \mathrm{~Hz}$ represented the first-order brush switching frequency, second-order electro-magnetic force excitation, and sixth-order motor rotation speed. Rather than sound radiation directly from the motor, reflection from the base support 
was dominant at $532 \mathrm{~Hz}$. Similarly, reflection from the base support is clearly shown at $1452 \mathrm{~Hz}$, $3076 \mathrm{~Hz}$, and $8456 \mathrm{~Hz}$. Sound radiated by electro-magnetic force excitation is shown at $764 \mathrm{~Hz}$. In addition, sound radiated by electro-magnetic force excitation is shown at frequencies $1024 \mathrm{~Hz}$, $1280 \mathrm{~Hz}$, and $1792 \mathrm{~Hz}$. The cause of the noise radiated at $1360 \mathrm{~Hz}$ may be due to the internal resonance rather than motor housing vibration. A relatively low response is shown in Figure 5b,d due to structural excitation of the motor housing, but a relatively high level of spatial-averaged sound pressure is shown in Figure 6 at $1360 \mathrm{~Hz}$, which indicates motor internal resonance. One of the possibilities for the sound source at $1360 \mathrm{~Hz}$ is the internal acoustic resonance, but further investigation is required to confirm it. Radiated sound from the motor bottom cap is shown at $4680 \mathrm{~Hz}$. Source of sound radiation at $4956 \mathrm{~Hz}$ is possibly due to coupled structural-acoustic resonances or acoustic resonances rather than by electro-magnetic force excitation, but further investigation is required to confirm it.

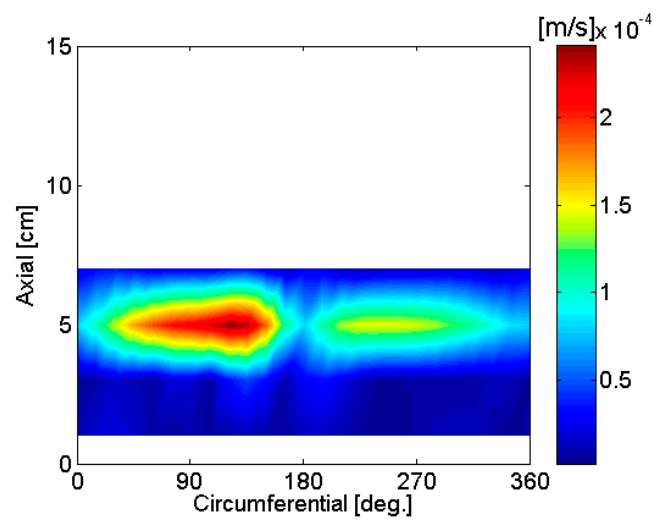

(a)

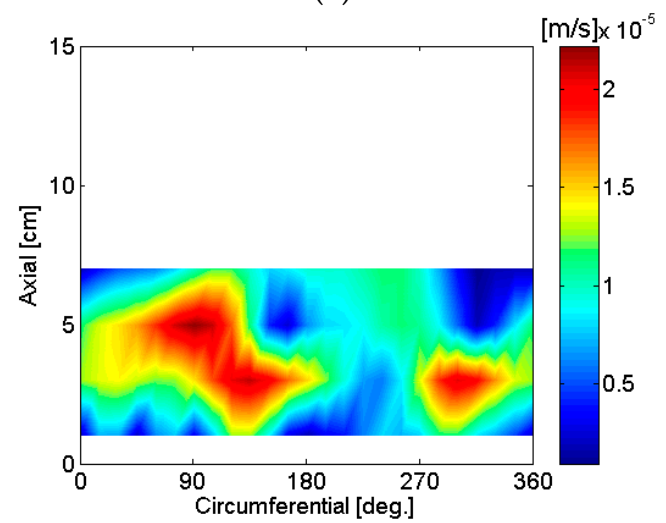

(c)

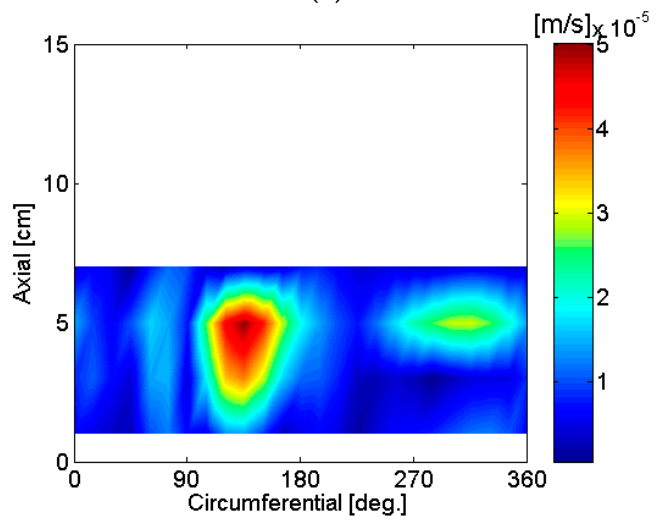

(e)

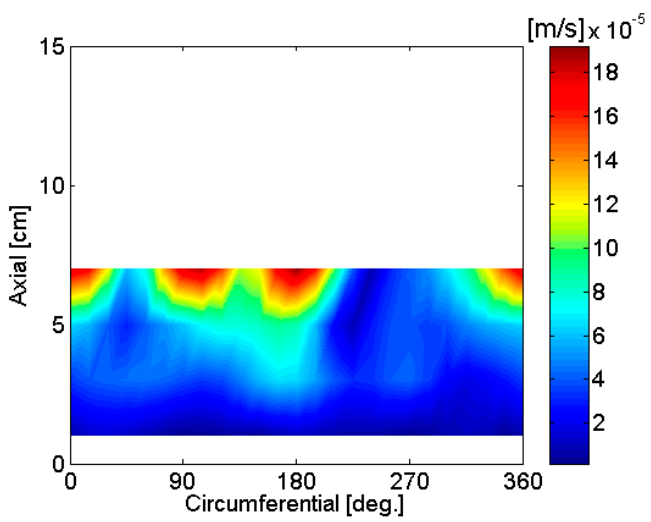

(b)

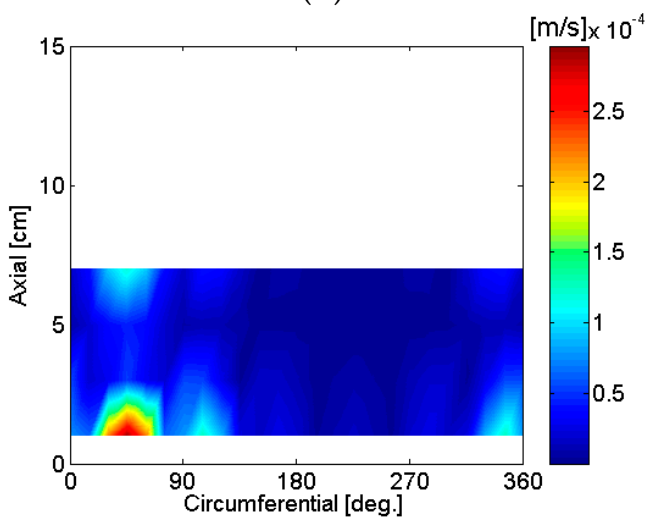

(d)

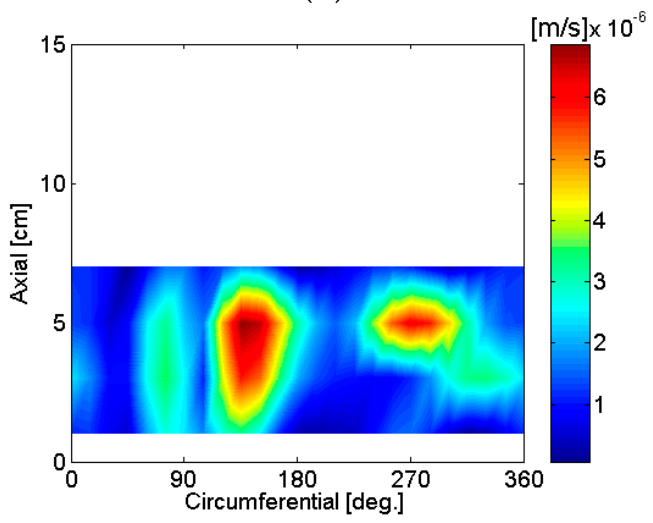

(f)

Figure 7. Cont. 


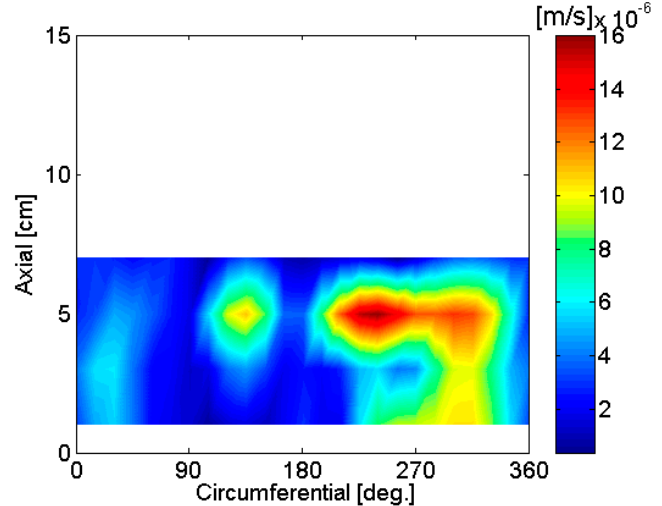

(g)

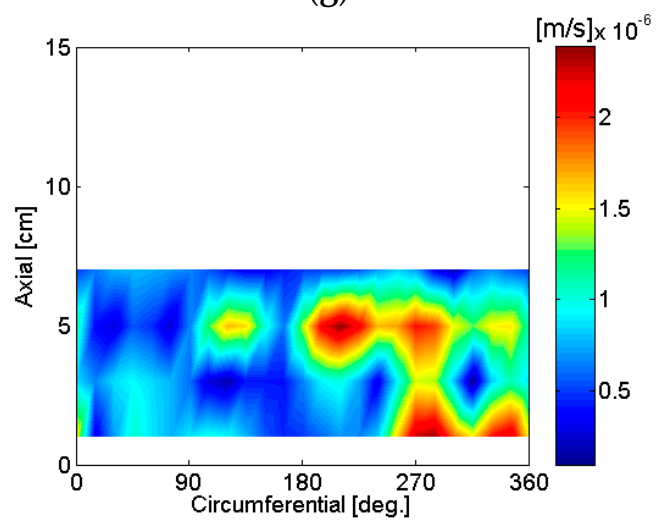

(i)

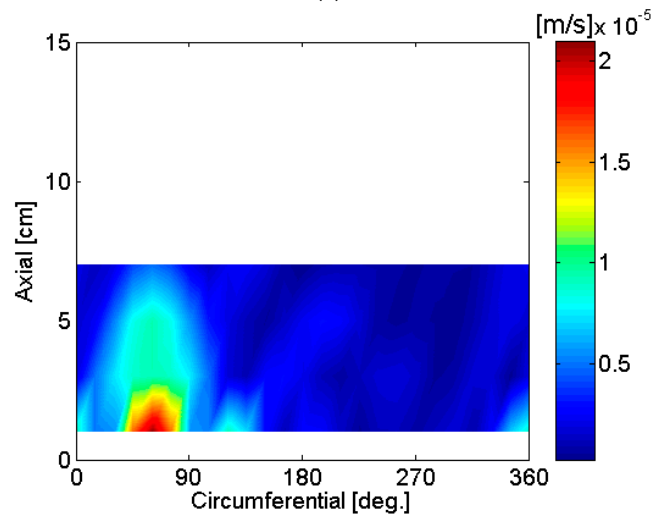

(k)

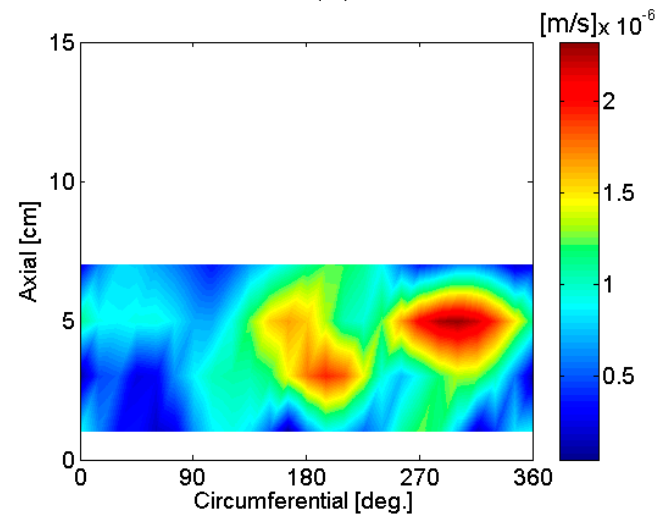

(m)

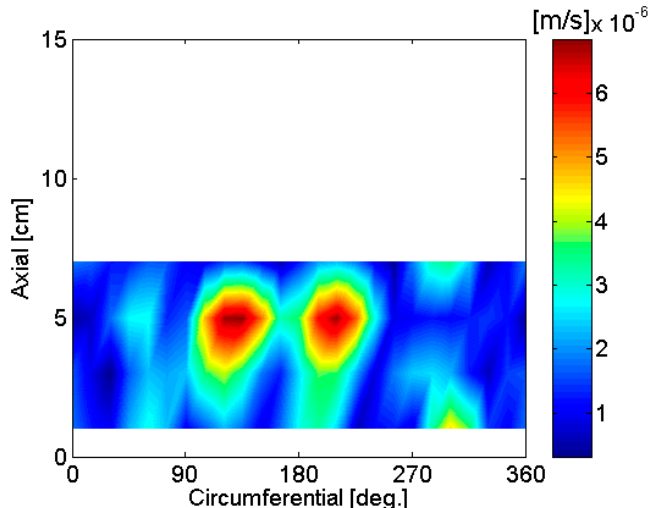

(h)

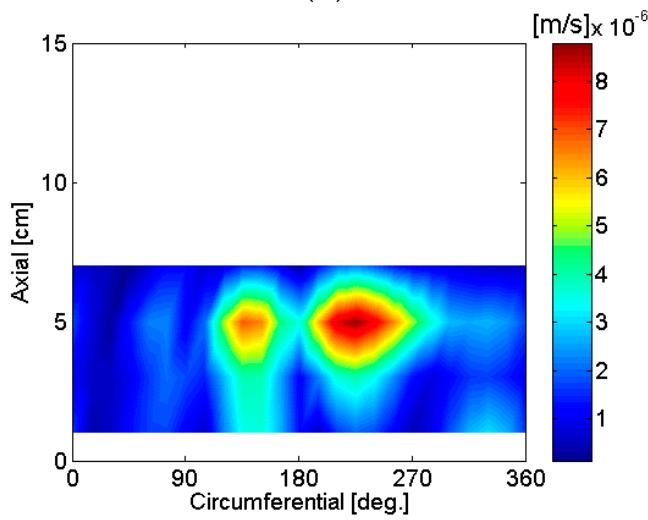

(j)

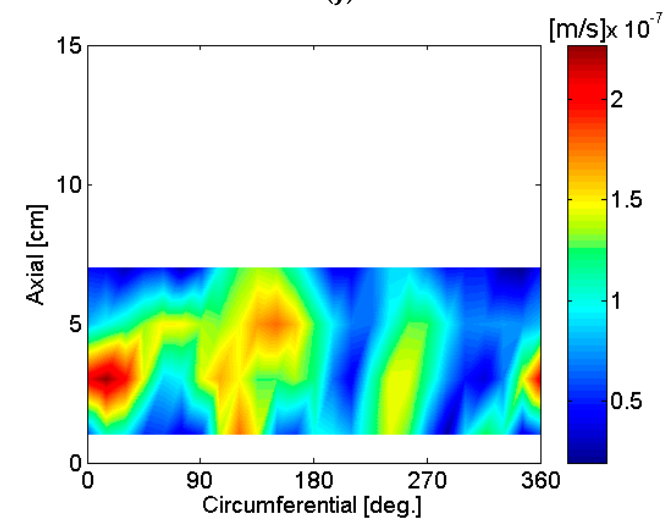

(1)

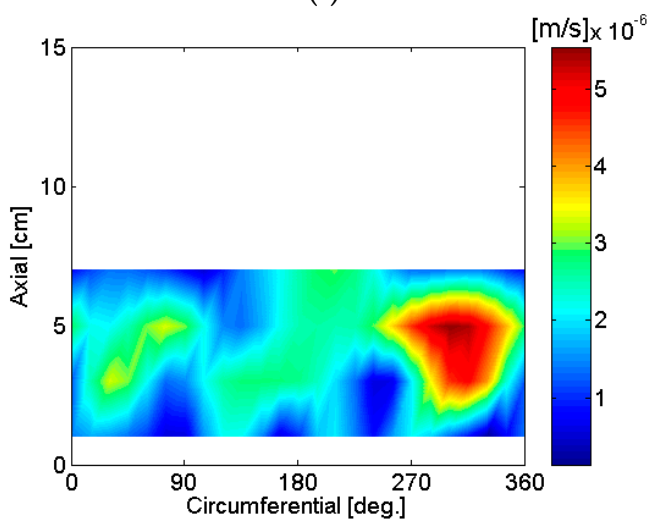

(n)

Figure 7. Cont. 


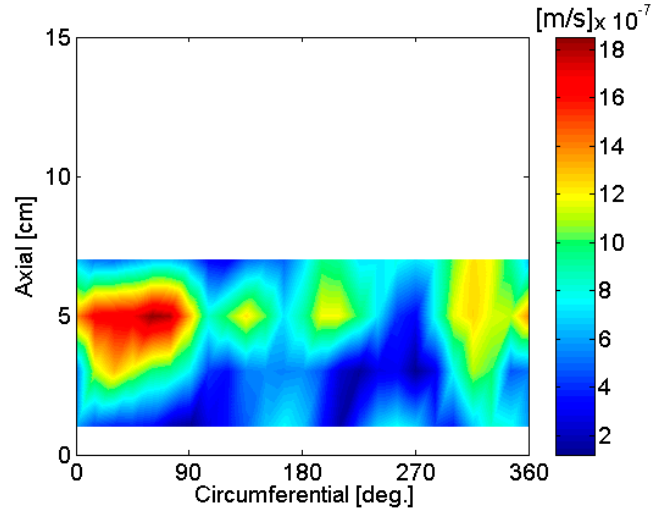

(o)

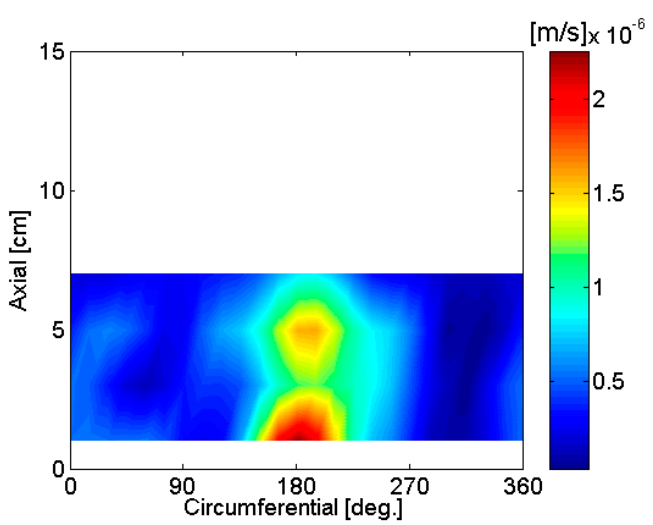

$(\mathbf{p})$

Figure 7. Reconstructed particle velocity of a motor supported on an aluminum base: (a) $84 \mathrm{~Hz}$; (b) $252 \mathrm{~Hz}$; (c) $508 \mathrm{~Hz}$; (d) $532 \mathrm{~Hz}$; (e)764 Hz; (f) $1024 \mathrm{~Hz}$; (g) $1280 \mathrm{~Hz}$; (h) $1360 \mathrm{~Hz}$; (i) $1452 \mathrm{~Hz}$; (j) $1792 \mathrm{~Hz}$; (k) $3076 \mathrm{~Hz}$; (1) $4680 \mathrm{~Hz}$; (m) $4956 \mathrm{~Hz}$; (n) $5124 \mathrm{~Hz}$; (o) $7192 \mathrm{~Hz}$; (p) $8456 \mathrm{~Hz}$.

Circular ring mode shape, $w_{3 \mathrm{n}}(\theta)$, is represented as [17]

$$
w_{3 n}(\theta)=A_{\mathrm{n}} \cos [n(\theta-\Phi)]
$$

where $\theta$ is angle in circular direction, $\Phi$ is phase angle, and $n$ is mode number. Circular ring mode shape is shown in Figure 8 for the cases of $n=0,1$ and 2 .

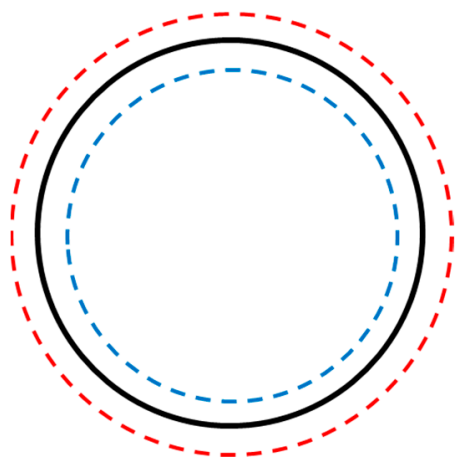

(a)

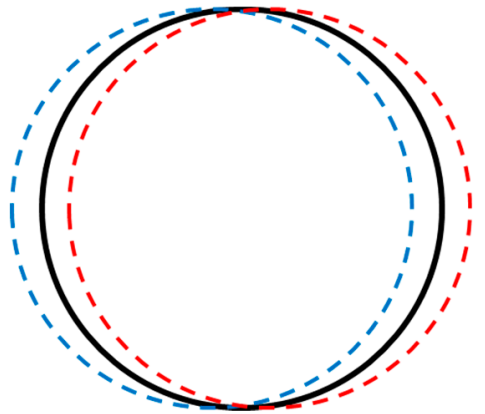

(b)

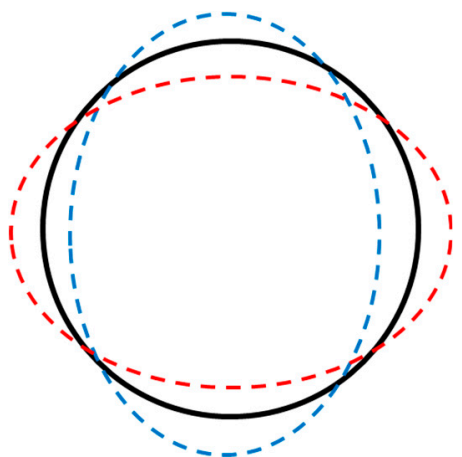

(c)

Figure 8. Circular ring mode shapes: (a) $n=0$ mode; (b) $n=1$ mode; (c) $n=2$ mode.

Sound radiated by electro-magnetic force excitation and possibly a combination of circular ring $n=0$ and $n=2$ modes for the center and bottom part of the motor housing are shown at $5124 \mathrm{~Hz}$ in Figure 7h. For the circular ring mode shapes shown in Figure 8, the $n=2$ mode shape consisted of four maximum magnitude values with opposite phase. Four peaks are shown at the bottom of the motor housing particle velocity reconstruction results at $5124 \mathrm{~Hz}$, which indicate circular ring $n=2$ mode at the open section of the motor housing. Similarly, sound radiated by electro-magnetic force excitation and circular ring $n=2$ mode for the center of the motor housing are shown at $7192 \mathrm{~Hz}$ in Figure $7 \mathrm{o}$. The response to structural excitation of the motor housing is shown in Figure $5 b$, and spatially-averaged sound pressure is shown in Figure 6a, which agrees very well with the particle velocity reconstruction results at both $5124 \mathrm{~Hz}$ and $7192 \mathrm{~Hz}$. Even though there are some variations in motor run-up operation measurements depending on measurement location, measurements of motor run-up operation indicate a modal response from the motor housing at both $5124 \mathrm{~Hz}$ and $7192 \mathrm{~Hz}$. 


\section{Conclusions}

Measurement and analytical work related to motor noise sources are relatively few, possibly due to the diversity of motor types and complexity of noise sources. In the present work, noise radiated from a small DC motor was measured, and radiated noise due to electro-magnetic excitation and structural resonance by housing were clearly shown to match three different types of measurement results, verifying the accuracy of the procedures. Accurately identifying noise and vibration sources for small motors is challenging due to the small physical dimensions of these machines and their relatively wide frequency range. The range of frequencies for the motor shown in the present work was $84 \mathrm{~Hz}$ to $7192 \mathrm{~Hz}$, and the highest frequency that avoided spatial aliasing of the measurements was $8575 \mathrm{~Hz}$. Overall, major sources of motor noise and vibration were electro-magnetic forces, internal resonance, and motor housing resonance. Unbalanced forces on the rotor, top cooling holes on the motor housing, and the switching of brushes were also dominant sources of noise at $84 \mathrm{~Hz}, 252 \mathrm{~Hz}$, and $508 \mathrm{~Hz}$, respectively, which is clearly shown through the reconstructed particle velocity of source surfaces via measurement pressure.

Reconstruction of particle velocity on source surfaces via measurement pressure was very useful for identifying sources of noise in small motors over a wide range of frequencies. Noise radiation from the base support of the motor was accurately identified from the reconstruction. Also, spatially-averaged measurement pressure confirmed the results of the motor run-up test and the response to a structural impulse from an impact hammer. Noise radiated due to the rotating part of the motor and motor housing was clearly shown by the motor run-up test.

Motor run-up test is very useful for identification of sound radiation due to resonances and rotating parts of the motor. However, a relatively strong source, such as frequency of $1360 \mathrm{~Hz}$, was not identified by using a run-up test due to its directivity. Results using only a small number of run-up test measurement locations may not be accurate, and enough number of measurement locations should be taken for accurate source identification.

Even though for the small motor shown in the present work, the source of noise is complicated, including such as structural resonance, acoustic resonance, and possibly coupled structural-acoustic resonance. Internal acoustic resonance was not identified using a run-up test with a relatively small number of measurement locations or impulse tests. However, internal acoustic resonance can be inferred from the reconstructed particle velocity on housing and frequencies of excitation. Further work is required to characterize internal resonance of motors in more detail.

It is difficult to verify measurement results accurately using only one type of measurement. However, by implementing three types of measurements simultaneously, sources of small motors can be identified more accurately.

Acknowledgments: This work was supported by a research grant from Kongju National University in 2016.

Conflicts of Interest: The author declares no conflict of interest.

\section{References}

1. Zhu, Z.Q.; Ishak, R.D.; Howe, D. Analysis of cogging torque in brushless machines having nonuniformly distributed stator slots and stepped rotor magnets. IEEE Trans. Magn. 2005, 41, 3910-3912. [CrossRef]

2. Hsiao, C.; Yeh, S.; Hwang, J. A novel cogging torque simulation method for permanent-magnet synchronous machines. Energies 2011, 4, 2166-2179. [CrossRef]

3. Espidola-Lópec, E.; Gomez-Espinosa, A.; Carrillo-Serrano, R.V.; Jáuregui-Correa, J.C. Fourier series learning control for torque ripple minimization in permanent magnet synchronous motors. Appl. Sci. 2016, 6, 254. [CrossRef]

4. Lee, H.J.; Chung, S.U.; Hwang, S.M. Noise source identification of a BLDC motor. J. Mech. Sci. Technol. 2008, 22, 708-713. [CrossRef]

5. Williams, E.G. Fourier Acoustics: Sound Radiation and Nearfield Acoustical Holography; Academic Press: London, UK, 1999; ISBN 0-12-753960-3. 
6. Weinreich, G.; Arnold, E.B. Method for measuring acoustic radiation fields. J. Acoust. Soc. Am. 1980, 68, 404-411. [CrossRef]

7. Williams, E.G.; Dardy, H.D.; Washburn, K.B. Generalized nearfield acoustic holography for cylindrical geometry: Theory and experiment. J. Acoust. Soc. Am. 1987, 81, 389-407. [CrossRef]

8. Steiner, R.; Hald, J. Near-field acoustical holography without the errors and limitations caused by the use of spatial DFT. In Proceedings of the ICSV6, Copenhagen, Denmark, 5-8 July 1999.

9. Hald, J. Patch near-field acoustical holography using a new statistically optimal method. In Proceedings of the INTER-NOISE 2003, Jeju, Korea, 25-28 August 2004; pp. 2203-2210.

10. Cho, Y.T.; Bolton, J.S.; Hald, J. Source visualization by using statistically optimized near-field acoustical holography in cylindrical coordinates. J. Acoust. Soc. Am. 2005, 118, 2355-2364. [CrossRef]

11. Cho, Y.T.; Bolton, J.S. Visualization of automotive power seat slide motor noise. In Proceedings of the NOISE-CON 2014, Fort Lauderdale, FL, USA, 8-10 September 2014.

12. Kompella, M.S.; Davies, P.; Bernhard, R.J.; Ufford, D.A. A technique to determine the number of incoherent sources contributing to the response of a system. Mech. Syst. Signal Process. 1994, 8, 363-380. [CrossRef]

13. Kwon, H.S.; Kim, Y.J.; Bolton, J.S. Compensation for source non-stationarity in multi-reference, scan-based nearfield acoustical holography. J. Acoust. Soc. Am. 2003, 113, 360-368. [CrossRef] [PubMed]

14. Kreyszig, E. Advanced Engineering Mathematics, 8th ed.; John Wiley \& Sons, Inc.: New York, NY, USA, 1999; ISBN 0-471-33328-X.

15. Thomson, W.T.; Dahleh, M.D. Theory of Vibration with Applications, 5th ed.; Prentice-Hall, Inc.: Upper Saddle River, NJ, USA, 1998; ISBN 0-13-649310-6.

16. PCB PIEZOTRONICS Model: 086C03. Available online: www.pcb.com/products.aspx?m=086C03 (accessed on 8 February 2018).

17. Soedel, W. Vibrations of Shells and Plates, 2nd ed.; Marcel Dekker, Inc.: New York, NY, USA, 1993; ISBN 0-8247-9035-9.

(C) 2018 by the author. Licensee MDPI, Basel, Switzerland. This article is an open access article distributed under the terms and conditions of the Creative Commons Attribution (CC BY) license (http:/ / creativecommons.org/licenses/by/4.0/). 